\title{
Key Technology of Manufacturing Information-Digital Design and Manufacturing
}

\author{
Jiang Yi, Xu Li \\ NanChang Institute of Science \& Technology
}

\begin{abstract}
The world economic competition pattern is undergoing profound changes, the main developed countries have proposed the re industrialization strategy, and launched a major move to rely on technological innovation to revitalize the manufacturing industry, a new round of industrial revolution is deepening. Manufacturing digital intelligence is the core technology of the new industrial revolution. On the one hand, it is the common cause of mechanical product innovation to improve the product function, performance and market competitiveness. On the other hand, it is also a common cause of manufacturing technology, which is also the common technology to improve product design, manufacturing and management.
\end{abstract}

Keywords-digital design and manufacturing; digital; intelligent; mechanic product innovation

\section{INTRODUCTION}

With the rapid development of global economic integration and the rapid development of information technology, the modern manufacturing enterprise environment has changed greatly, the main characteristics of the product life cycle is shortened, the delivery time has become the main competition factor, the market and the competition has been formed. Modern manufacturing industry has been adapted to the development of new models and new philosophy, its core is: in the manufacturing enterprises in the full implementation of digital design and manufacturing technology, through the product life cycle in all aspects of the popularization and deepening of computer aided technology, system and set technology applications, so that the enterprise's design, manufacturing, management technology level, promoting the traditional industry in all aspects of technology updates, so that enterprises in the continuous dynamic and unpredictable global market competition environment and continue to expand its competitive advantage.

Digital design and manufacture is an important part of the computer aided technology, system and integrated technology, it is to the development of networked manufacturing and virtual technology, it makes the original traditional manufacturing industry into the intellectual industry, enable enterprises, mainly through resources, such as labor, capital, equipment, competition becomes the Chihpen type of innovative ability is the focus of competition. This is the most important feature of the era of knowledge economy.

\section{DigITAL DESIGN AND MANUFACTURING}

Digital design and manufacturing technology is the use of computer software and hardware and network environment, to achieve the whole process of product development, a technology, which is based on the network and computer aided product data model, comprehensive simulation of product design, analysis, assembly, manufacturing and other processes.

From the past, present and future of product formation (product plan - design concept - detailed design - preparation for production): From yesterday's process to the process chain and the development of the process flow to tomorrow. See Fig .1. The formation process of the products is more and more high, and the efficiency is also improved. 


\section{Product Plan Detailed Design $\Rightarrow$ Production Preparation}

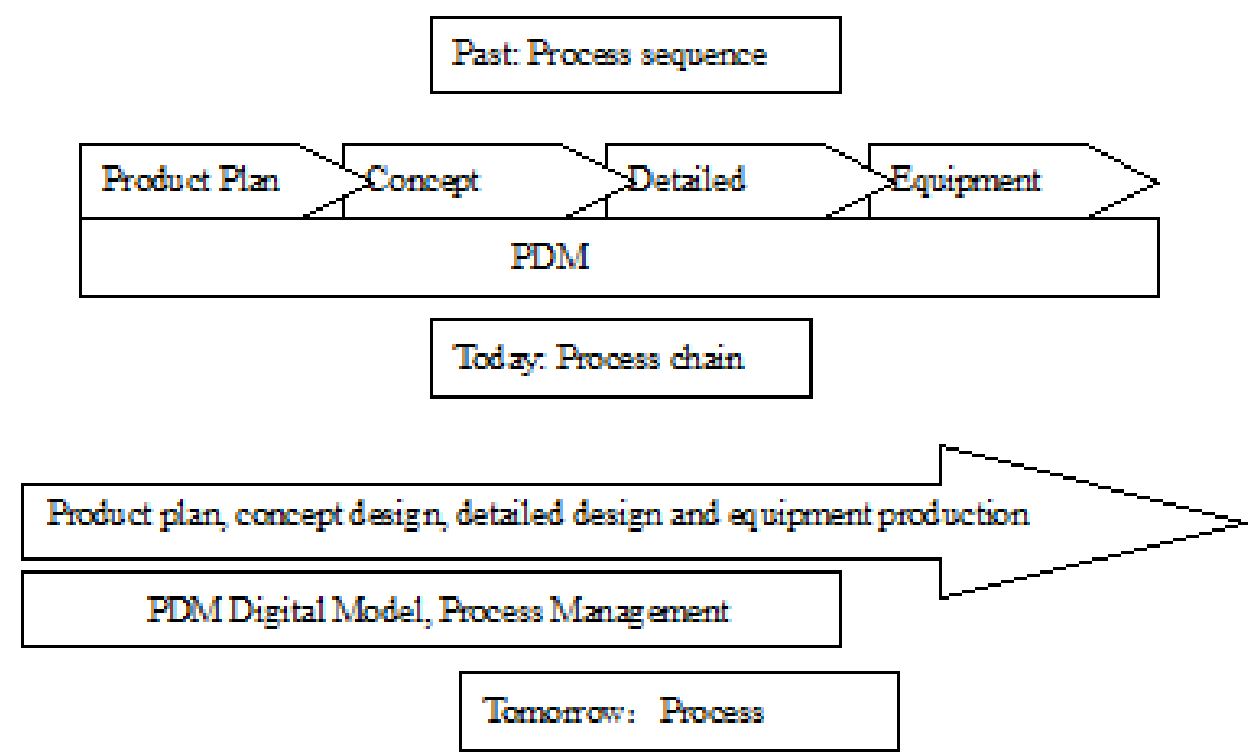

Figure 1. Evolution of Product Formation

In terms of past, present and future development of product design, it develops from the hand drawn map to $\mathrm{CAD}$ and then virtual reality, as shown in Fig .2. And they are different in each development process, in the past focus on the parts, focus on the development and manufacturing; today's focus is on the prototype, focus on the formation of the product process; the future focus on the product, focusing on the product life cycle. That is, product design develops from a point to a line and then surface.

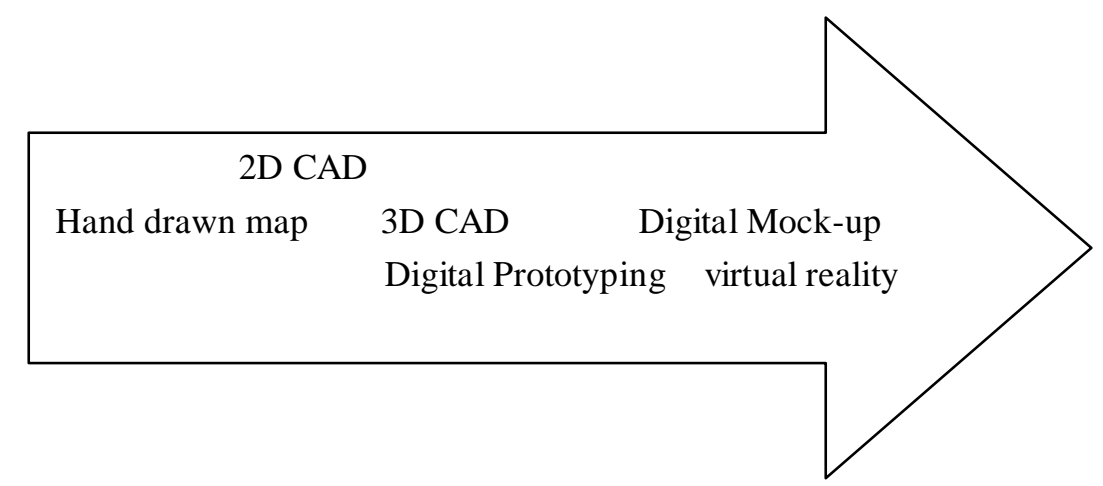

Figure 2. Evolution of Product Design

\section{Connotation AND DeVelopment of Digital Design AND MANUfacturing}

The digital design and manufacture mainly includes the computer aided design CAD, manufacturing CAM, process design CAPP, engineering analysis CAE, product data management PDM and so on. The content of its digital design is to support the whole process of product development, support enterprise product innovation design, support product related data management, support enterprise product development process control and optimization, etc. The relationship between them is shown in Fig .3. 


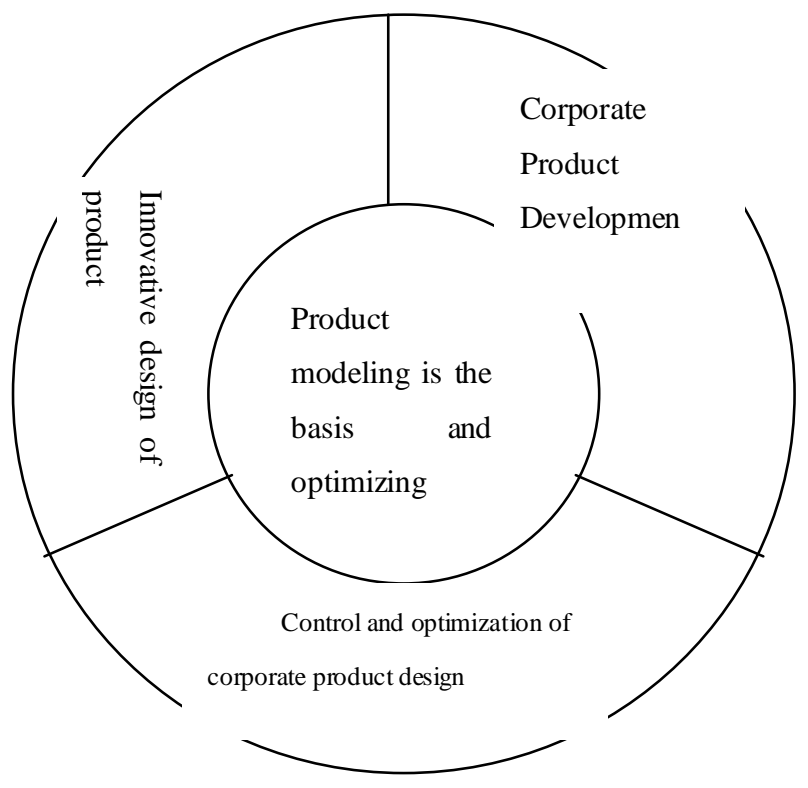

Figure 3. Connotation of Digital Design

Because of the research of integrated technology and tools such as CAM and CAD, it has been solved in the process of product processing. Show as Fig .4. It is the key technology of manufacturing state and process, the representation of non symbolic manufacturing knowledge, reliable access to manufacturing information, quality, classification and evaluation.

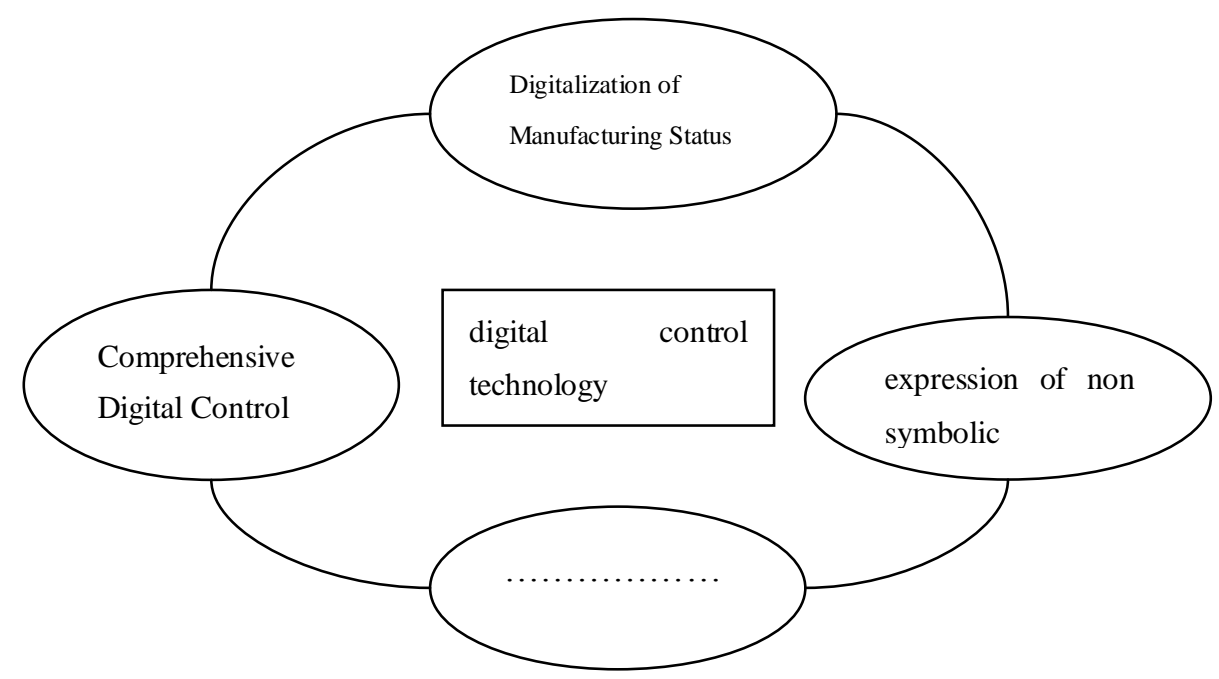

Figure 4. Connotation of Digital Manufacturing

IV. Development Trend of Digital Design AND MANUFACTURING TECHNOLOGY

The general trend of the development of advanced manufacturing technology can be summarized as follows: precision, flexibility, networking, virtualization, digital, intelligent, clean, integration and management innovation, etc. Digital design and manufacturing technology is the basis of advanced manufacturing technology. With the continuous improvement of computer technology, the popularization of Internet network technology, as well as the different needs of users, CAE, CAPP, CAD, CAM, 
PDM (C4P) and other technology is also in constant development. The integration technology is also moving forward.

$\mathrm{CAD} / \mathrm{CAE} / \mathrm{CAPP} / \mathrm{CAM} / \mathrm{PDM} \quad(\mathrm{C} 4 \mathrm{P})$ integration technology based on the network is to achieve full digital design and manufacturing products.

In the process of CAD/CAM application, it can improve the efficiency and quality of product development by using PDM technology to realize the concurrent engineering. Enterprises through the PDM can product functional configuration, series, standard parts, borrowing and purchased parts and components to reduce repeated design a. Product design and manufacturing in PDM environment, through the integration of $\mathrm{CAD} / \mathrm{CAE} / \mathrm{CAPP} / \mathrm{CAM}$ and other modules, to achieve product design and the entire digital manufacturing.

$\mathrm{CAD} / \mathrm{CAE} / \mathrm{CAPP} / \mathrm{CAM} / \mathrm{PDM}$ technology is mainly used to realize product design, process and manufacturing process and management of digital; enterprise resource planning ERP is to achieve enterprise production, supply, sales, human, financial, material management as the goal; supply chain management SCM is used to realize the logistics management between enterprise and enterprise, customer relationship management CRM can help companies build, mining and improve the relationship with customers.

\section{V.CONCLUSION}

In the process of manufacturing digital intelligence, we should firmly establish the consciousness of innovation service development, further emancipate the mind, and carry out the scientific and technological achievements of scientific and technological achievements, which are the first productive forces, which is the first productive forces, especially for the promotion of scientific and technological achievements. One is to give full play to the advantages of system of our country, government leading, overall planning, step-by-step implementation, key breakthrough, promoting, mobilized an army, elites, implement organizational innovation; second is to accelerate the integration of informationization and industrialization depth, through the digital intelligent of is the core of information technology to transform upgrade traditional manufacturing industry, integrated innovation; establishing innovation system to enterprises as the main body, the market as the guidance, the combination of tight binding, in particular to strengthen the technological innovation of enterprises in the main role, forming manufacturing digital intelligent innovation alliance, for collaborative innovation.

Digital design and manufactirng has proposed a new issue to traditional manufacturing revolution as well as traditional mechanical engineering education; the emergence of the Internet is more important than previous industrial revolution, and the changes will be even greater than industrial revolution.

\section{REFERENCES}

[1] Siegert K. CNC-hydraulic multipoint blank-holder system for sheet metal forming presses. Ann CLRP(1993), 42(1): 315 322

[2] R Sowerby, E Che, J L Duncan. The Modeling of Sheet Metali Stamping. Int. J. Mech. Sci. 1986. 28(7) : 415-430

[3] Klaus-Jurgen Pahl. New developments in multi-point die-cushion technology. J. Matterials Processing Technology, 1997, 71: $168 \sim 173$

[4] I. M. Ibrahim, D. A. Crolla and D. C. Barton. Effect of frame flexibility on the ride vibration of trucks.Computer \& Slructure, 1996(4):709 713

[5] Evangelos J. Sapountzakis and John T. Katsikadelis. A new model for slab and Beanmstructrues - comparison with other models.Computer \& Structure, 2002(5-6) :459 470

[6] F.L.Zhao, S.K.Tso, Paul S.Y.Wu. A cooperative agent modeling approach for process planning. Computer in Industry. 41 (2000): 83 97.

[7] Downlatshahi, S and Ashok, MS. Design Optimization in Concurrent Engineering: A Team Approach. Concurrent Engineering: research and Application, 1997, 5(5): 145-154.

[8] Jozsef Vancza\&Andras Markus. Experiments with the Integration of Reasoning, Optimization and Generalization in Process Planning. Advances in Engineering Software, 1996, 25:29-39.

[9] Q. Peng, F.R.Hall, P.M.Lister. Application and evaluation of VR-based CAPP system. Journal of Materials Processing and Technology. 107(2000): 153 159.

[10] Carl Bloch and Ranga Ranganathan. Process-Based Cost Modeling. IEEE Transaction on Components, Hybrids, and Manufacturing Technology, 1992, 15(3): 288-294.

[11] Fen, C.J, Kusiak, A., and Huang, C. Cost Evaluation in Design with form features. Computer-Aided Design, 1996,28(11): 879-885.

[12] F. Zhang, Y.F. Zhang, A.Y.C.Nee. Using Genetic Algorithms in Process Planning for Job Shop Machining. IEEE Transactions on Evolutionary Computation, 1-4(1997): 278-289. 